Published in Construction and Building Materials: doi.org/10.1016/j.conbuildmat.2020.121089

\title{
A review on acoustic emission monitoring for damage detection in masonry structures
}

Els Verstrynge ${ }^{\dagger}$, Giuseppe Lacidogna*, Federico Accornero*, Adrienn Tomor ${ }^{\#}$

${ }^{+} K U$ Leuven, Civil Engineering Department, Building Materials and Building Technology Section, Kasteelpark Arenberg 40, 3001 Heverlee, Belgium.

*Politecnico di Torino, Department of Structural, Geotechnical and Building Engineering, Corso Duca degli Abruzzi 24, 10129 Torino, Italy.

${ }^{\#}$ Brunel University London, Department of Civil and Environmental Engineering, Uxbridge, UB8 3PH, United Kingdom

Keywords: acoustic emission monitoring, historical masonry, damage detection, fracture analysis, ultrasonic wave propagation

\begin{abstract}
Acoustic emission monitoring is widely used for damage detection in materials research and for site monitoring. Its use for masonry structures is however challenging due to the highly heterogenic nature of masonry and rapid signal attenuation. However, the non-invasive nature and high sensitivity of the technique also provide interesting opportunities, especially for historical masonry structures, to locate damage, identify severity of damage and rate of deterioration. Aim of this paper is to provide an extensive literature review on the application of the acoustic emission technique for masonry structures, addressing specific challenges and recent findings. AE-based methods for damage assessment in masonry are discussed in view of monitoring approaches, wave propagation, source location and crack development under static, fatigue and creep loading. Site applications are discussed for identifying crack location and crack propagation in historical masonry towers, buildings and masonry arch bridges. The paper concludes with future challenges identified in this research field.
\end{abstract}

\section{Introduction}

The Acoustic Emission ( $A E$ ) technique is a valuable non-destructive monitoring technique for material research and field monitoring of structures, that can identify fracture development through detection of high-frequency elastic waves that are being produced by the fracture process itself [1]. Analysis of waveform properties can be used to indicate crack location and severity, and analysis of individual fracture modes with varying signals characteristics enables to assess dominant fracture mechanisms. 
In civil engineering, $A E$ technique is widely used for monitoring concrete, metal and composite structures [1-3], as well as following-up setting of fresh mortars and concrete [4,5]. Although its application for masonry is so far relatively limited, it has been shown to be a highly useful tool for identifying damage locations and propagation of damage [6-11]. Since AE is a non-invasive and non-destructive monitoring technique, it is ideally suited for use in the assessment of historic masonry structures that are subjected to high sustained loads [12, 13], fatigue loads [14, 15] or are exposed to seismic risk $[16,17]$.

The purpose of this paper is to provide an overview of recent research and associated existing challenges for AE monitoring of masonry. For homogeneous materials (e.g. steel) ultrasonic wave propagation is relatively straightforward and cracks can be detected from long distances with accuracy. As masonry is a highly non-homogeneous material with relatively high attenuation, the application of $A E$ monitoring is more challenging. AE technique can however provide highly useful information on the damage location and propagation.

Although the focus of the paper is on AE testing in masonry, for some aspects such as source location and damage analysis methods, literature on concrete and rock testing is included to get the full picture. The scope of the paper is limited to AE testing of fracture in brittle materials, excluding steel and reinforced concrete, and excluding general ultrasonic testing in which the signal is induced by an actuator and not by the fracture process itself. For a general introduction and working principles of the acoustic emission technique, the reader is referred to [2].

Challenges for AE-based damage monitoring of masonry are discussed with recent developments and brief literature review in Section 2. Section 3 focuses on experimental testing of masonry under laboratory conditions. Site monitoring and damage assessment are discussed for historical masonry buildings in Section 4.1 and for masonry arch bridges in Section 4.2 together with literature review and cases studies. The paper concludes with outstanding issues and an outline of future research needs.

\section{AE-based damage monitoring approaches for masonry}

An acoustic emission is a high-frequency, elastic wave that is produced by stress redistributions and micro-structural changes within a material, e.g. micro-crack formation. With the $A E$ technique, fracture progress can be assessed through counting $A E$ events, parameter-based analysis or signal-based analysis. The first approach attempts to relate the cumulative number of $A E$ events or rate of $A E$ activity to the rate of damage progress. An $A E$ hit is defined as a signal captured by an AE sensor when crossing a predefined amplitude threshold. When a hit is captured by multiple sensors within a restricted timeframe, the collection of signals is referred to as an $A E$ event. AE signals are recorded in millivolts and typically presented on a logarithmic scale in decibels $\left(\mathrm{dB}_{\mathrm{AE}}\right)$. Piezo-electric sensors with frequency ranges between 30 and $150 \mathrm{kHz}$ are generally used for masonry structures and sensors with higher frequency ranges, up to $800 \mathrm{kHz}$ for small-scale samples and masonry constituents (e.g. bricks and mortars). Optical fibre sensors 
have also been trialled for masonry, but so far with limited success due to high attenuation rate in masonry, which requires optimal sensor sensitivity [18-20].

\subsection{AE event counting}

AE event rate analysis for damage evaluation of concrete and masonry structures is discussed in the RILEM committee reports TC 239-MCM [21] and by Ishibashi et al. [22]. It was used to identify creep and fatigue deterioration processes in masonry and develop failure prediction models [8, 12]. AE event rate was also used to correlate salt crystallisation to pore network characteristics in limestones for historical buildings by Grossi et al. [23].

Under cyclic loading, the LOAD-CALM analysis method is often applied in masonry [2, 24, 25]. This technique relies on $A E$ event counting and compares $A E$ activity in subsequent loading cycles. The LOAD ratio, also known as the Felicity ratio, indicates the ratio between the load at the start of $A E$ activity in a current cycle and the maximum load in a previous cycle. A ratio of 1.0 represents the Kaiser effect, often referred to as the 'memory of the material' for previous maximum load levels. Upon the occurrence of internal damage in the material's micro structure, the ratio drops below 1.0. The CALM ratio represents the AE activity during the unloading phase and is therefore also an indication of the presence of internal defects. Hence, both ratios can be combined to assess the damage state [25]. For concrete testing this procedure is described in ISO 16837 [26]. In masonry, this approach is particularly useful as it compares AE activity in subsequent cycles of a load test on a structure. Hence, these ratios are less affected by the high attenuation in masonry, as would be the case for AE signal parameters such as amplitude and energy.

Cyclic three-point bending tests were performed on blocks of refractory masonry by Andreev at al. [24]. It was found that the LOAD-CALM analysis allowed differentiating the fracture progress in refractories of various brittleness and the AE-based damage limits from cyclic testing were related to the fatigue limits of the respective refractory materials. An on-site load test on a historical masonry vault was performed by Carpinteri et al. [27]. The test loading was carefully applied by means of water cushions, and AE counts were reported. Interestingly, AE activity was reported to start only upon exceedance of the previously reached maximum load level. This signifies an on-site recording of the Kaiser effect on a masonry vaulted structure.

Load-Calm analysis was used to quantify progressive damage in masonry walls under cyclic compressive loading by Shetty et al. [28], a representative example is shown in Figure 1. By comparing $\mathrm{AE}$ and digital image correlation results, damage limits established for concrete were found to be too conservative for masonry and further work is proposed to establish suitable limits for masonry structures. 


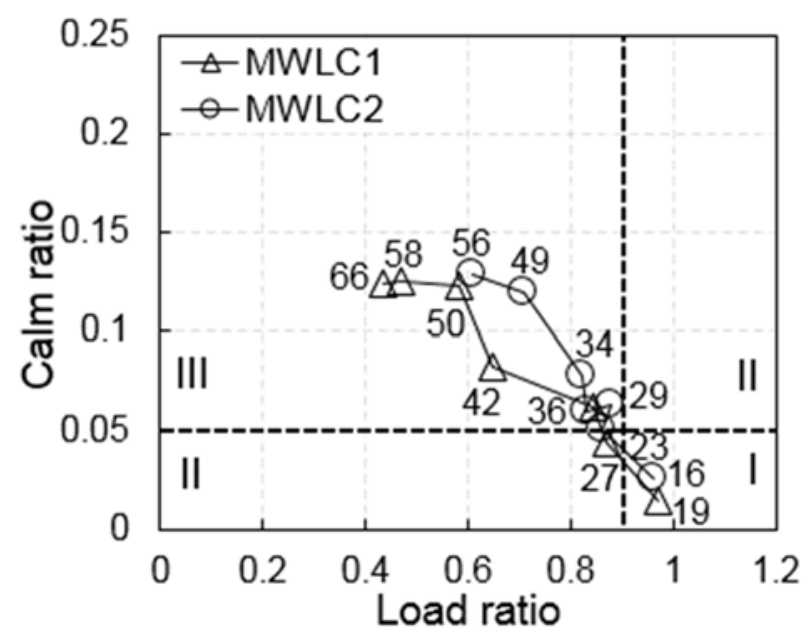

Figure 1: Representative Load-Calm ratios for two masonry wall samples with hybrid lime-cement mortar (MWLC1, MWLC2). Zone I indicates minor or no damage, II intermediate damage, and III heavy damage. Values are normalized compressive loads (in \%). Shetty at al. [28].

\subsection{Parameter-based and $b$-value analysis}

A parameter-based approach uses basic signal characteristics (such as counts, energy or maximum signal amplitude) to deduce information on the fracture process. An overview of $A E$ parameter-based damage assessment approaches was presented by De Smedt et al. [29] for high-temperature resistant refractory materials under fatigue loading and by Aggelis for concrete [30]. Parameters such as rise time, signal amplitude and average frequency were studied by Livitsanos et al. [31] to distinguish fracture modes in masonry and analyse signal characteristics for different brick and mortar types. The method applied in the latter study will be further discussed in the next section, as it is also referred to as a simplified signal-based analysis due to the use of the frequency characteristics of the waveform in this approach.

With reference to the field of seismology, $b$-value analysis is often used for concrete and masonry structures to evaluate the severity of damage. The $b$-value represents the distribution of amplitudes for AE events. During damage development a reduction of $b$-value indicates a coalescence of micro- into macro-cracks and likely critical damage development, leading to failure.

Detailed studies on $b$-value analysis in concrete were carried out by Carpinteri et al. [32] on concrete cores with various aspect ratios. An improved $b$-value method was proposed by Shiotani et al. [33] to quantify change in AE energy release during macro-crack development. Macro-crack development using $b$-value analysis on reinforced concrete beams under bending was studied by Colombo et al. [34]. The application of $b$-value analysis for masonry has however so far been limited. Anzani et al. [35] applied $b$-value analysis to evaluate compression failure in multi-leaf 
masonry walls. However the number of test specimens were too low to assess the efficacy of the method for masonry.

Parameter-based AE data and shift in $b$-value upon immediate failure can be interpreted using statistical and fractal analysis, taking the multiscale nature of the crack development process into account. The approach has shown that AE energy release occurs in a fractal (lacunar) domain with a dimension lower than 3.0. A multiscale criterion to predict the damage evolution has been formulated by Carpinteri et al. [36], showing that the $b$-value is related to the fractal dimension $D_{F}$, and that usually $2 b=D_{F}$ [37]. These considerations are explained in greater detail in the following paragraphs, as they form the basis of some of the case studies elaborated in Section 4.

The brittle failure of a material is a complex phenomenon which occurs when a structure progressively deteriorates, at first in a uncorrelated way reflecting the intrinsic heterogeneities (dislocations, flaws, etc.), or disorder. As the density of micro-cracks increases, the stress fields of the micro-cracks interact and they become correlated. The micro-cracks eventually coalesce into macro-cracks, developing the so-called quasi-brittle behaviour of the structure [38-40]. This quasi-brittle behaviour, typical of disordered materials, is characterized by well-defined precursors including changes in the ability to sustain stresses and variations in $A E$ trends, announcing the local or global structural failure [41, 42]. As a result of micro cracking, some of the stored strain energy is emitted as $A E$, see Figure 2, and can hence be used as a damage indicator [43-45].

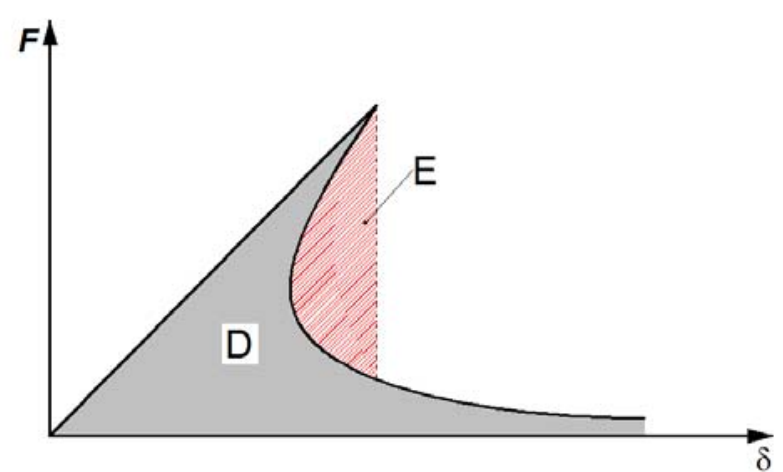

(a)

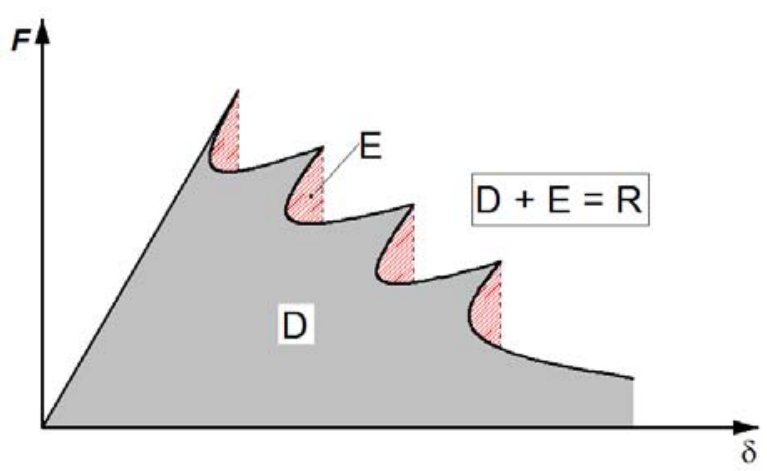

(b)

Figure 2: Load-displacement curves representing (a) brittle failure (single snap-back) and (b) softening behavior with multiple local instabilities (multiple snap-backs). Grey areas represent dissipated energy $(D)$, dashed areas are emitted energy $(E)$ which correlates to AE energy. $R$ is the total released energy $(D+E=R)$.

The emitted energy $E$ during micro-crack propagation has been demonstrated to occur in a fractal domain comprised between a surface and the structural volume $V$ [36]. As a result, the following size-scaling law can be assumed for the emitted $A E$ energy $E$ during damage:

$$
E \propto V^{D_{F} / 3}
$$


Where $V$ is the volume and $D_{F}$ the fractal exponent comprised between 2.0 and 3.0 [43]. For $L$ as the characteristic dimension of the specimen:

$$
V^{D_{F} / 3}=L^{3\left(\frac{D_{F}}{3}\right)}=L^{D_{F}}
$$

If $D_{F}=3.0$, damage will be distributed in the whole specimen volume, i.e., $L^{3}$, and if $D_{F}$ is approaching to 2.0 , damage will be organized on a preferential fracture surface, i.e., $L^{2}$.

During micro-crack propagation, the emitted $A E$ energy $E$ may be assumed proportional to the number $(N)$ of $A E$ events. The number of $A E$ events $(N)$ over a fractal domain, can therefore be considered as the fractal density of $A E$ events $\left(\Gamma_{A E}\right)$ :

$$
\Gamma_{A E}=\frac{N}{V^{D_{F} / 3}}
$$

At crack growth two mechanisms contribute to damage, i) fracture nucleation and ii) fracture growth, but without coalescing in the fracture surface. During the early loading phase, crack nucleation is the key mechanism and defects are likely to be spread uniformly in the structure, allowing a mean volumetric density of defects to be defined. Assuming $D_{F}=2 b$, the condition $D_{F}$ $=3$ implies $b=1.5$, with $b$ being the aforementioned $b$-value. This assumption is in agreement with experimental findings [46-48].

At imminent collapse, crack growth and coalescence take place and the majority of cracks develop near the final failure surface $[47,48]$. With the majority of cracks being concentrated in a narrow band around the final fracture surface the constant volumetric density cannot be defined consistently any more. The relationship between $D_{F}$ and the $b$-value results in $b=1.0$. The evolution of $D_{F}$ and the $b$-value during a loading test is indicated in Figure 3 . Decreasing $b$ value indicates increasing damage and increased crack sizes.
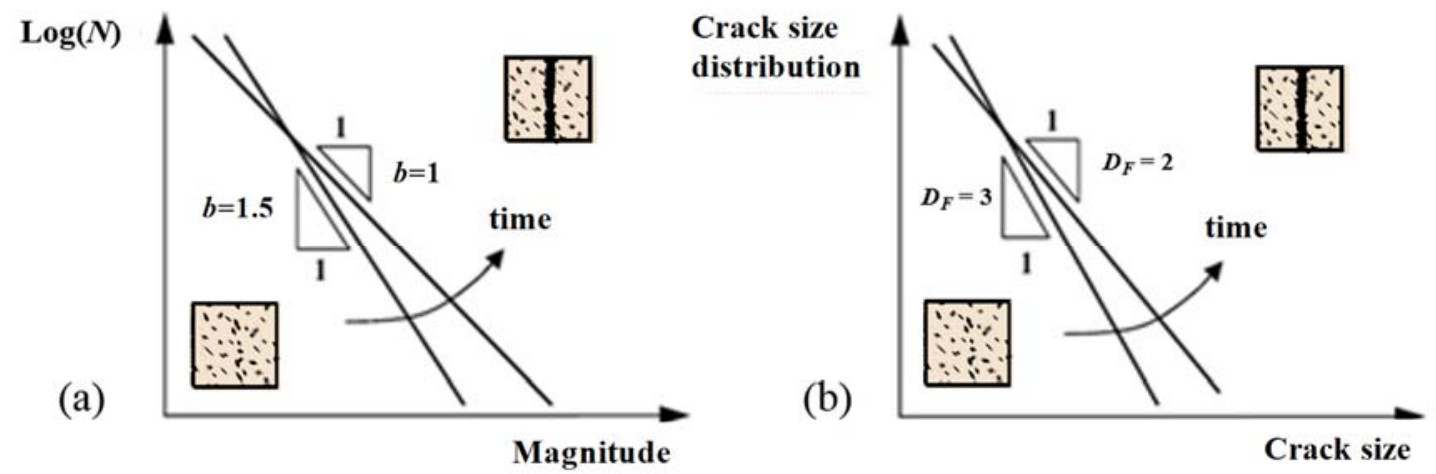

Figure 3: Evolution of (a) $b$-value and (b) theoretical crack size distribution during damage progress. Coalescence of micro-cracks into a narrow band around the final fracture is illustrated in the small inset figures. 


\subsection{Signal-based analysis}

A signal-based (or waveform) analysis requires high sampling rates and broadband AE sensors for characterising the complete waveforms and related fracture modes. It includes moment tensor analysis on located AE events to differentiate mode I (tensile) and mode II (shear) cracking [49]. Waveform-based analysis has been little used for masonry due to high attenuation rates and perturbation of the waveforms by the heterogeneous material. A study of AE signals in the frequency domain is discussed for masonry by Masera et al. [50].

As a compromise, a simplified signal-based analysis (also referred to as parameter-based analysis) can be applied for masonry using specific waveform parameters, such as 'RA' (rise time to maximum amplitude) and 'AF' (average frequency) [51-53]. For concrete testing, this approach is described in ISO 16838 [54]. Numerical studies have shown that the reliability of such classification depends on the heterogeneity of the material, wave propagation path and distance between source and sensor [55]. This is particularly relevant for masonry with rapid wave attenuation and large size specimens.

Waveform properties distort with increasing source-sensor distance and number of mortar joint crossings. The effect of an increasing wave propagation path on Average Frequency (AF) and Rise Time (RT) in masonry is shown in Figure 4 [56]. Both experimental and numerical results show increase in RT and slight decrease in AF, that is in agreement with similar studies on cementitious mortars [57]. As RT and AF are often used in simplified signal-based analysis to distinguish tensile and shear fracture, source-sensor distance should be limited and/or waveform distortions should be compensated for masonry structures. A method to compensate such alterations on waveform parameters was proposed for masonry by Livitsanos et al. in [58].

In the following sections, literature overview and recent findings will be presented for acoustic emission monitoring of masonry through laboratory experiments and site monitoring of historical buildings and masonry arch bridges. 

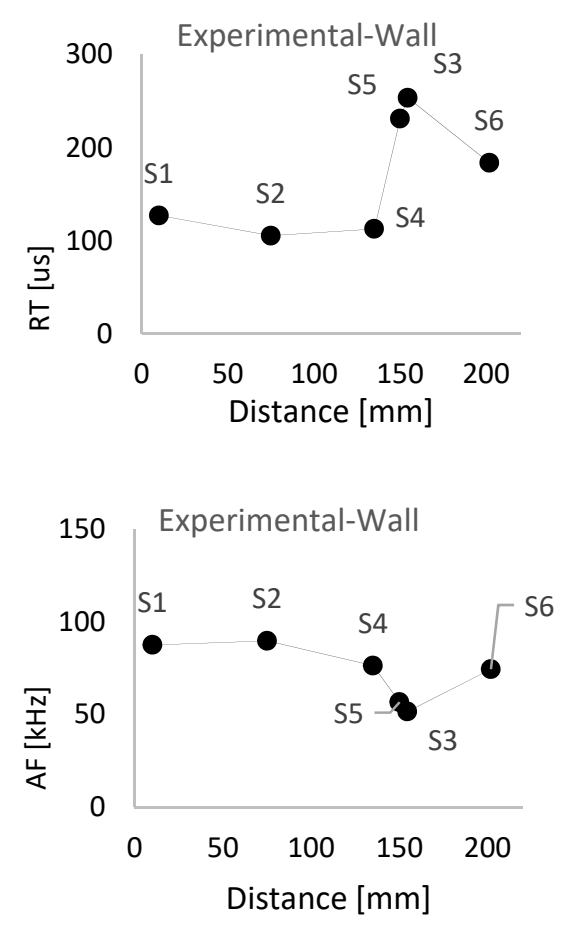

(a)
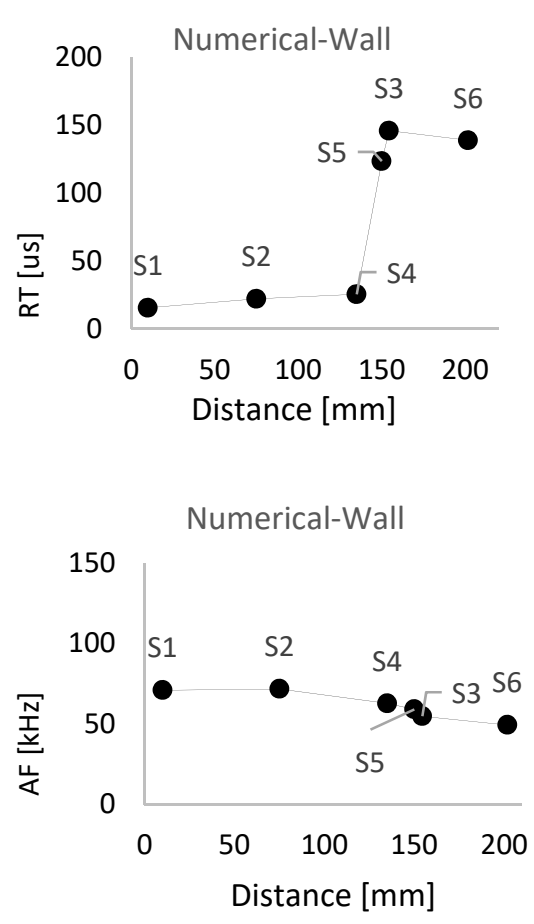

(b)

Figure 4: Effect of distance between crack location and AE sensor on Rise Time (RT) and Average Frequency (AF) obtained through (a) compression test and (b) numerical analysis. Figures adopted from [56].

\section{Experimental analysis of damage development}

The acoustic emission technique has shown great potentials for damage detection and fracture characterization of masonry during laboratory and field tests. As unreinforced masonry is typically subjected to compressive stresses, AE monitoring has been used for walls under uniaxial creep $[12,59]$, fatigue $[8,60]$ and cyclic tests [28]. Piezoelectric sensors as well as optical fibres for AE sensing have been tested by Verstrynge et al. [18] in a deep masonry beam (wall of approx. 95 (height) $\times 210$ (length) $\mathrm{cm}^{2}$, and $20 \mathrm{~cm}$ thickness) under bending, and results were compared with several other strain monitoring techniques. Acoustic emission sensing has also been applied to assess the efficacy or durability of repair techniques for historical masonry, such as grout injection of multi-leaf masonry [35], and composites with polymer- or mortar-based matrices for externally bonded strengthening [61].

The following sections firstly address AE wave propagation in masonry and source localization in small masonry walls subjected to compression tests. Secondly, it briefly reports a successful test series in which AE sensing provided essential information to monitor and fully understand creep damage progress. 


\subsection{AE wave propagation and source location}

As mentioned in the previous section, propagation of high-frequency acoustic emission waves in masonry is influenced by signal attenuation and distortion due to the heterogeneity of the material. Table 1 presents typical AE wave velocities and maximum source-sensor distances for masonry compared to other construction materials reported in the literature. The values are only indicative and dependent on the amplitude threshold during data acquisition and the frequency spectrum of the applied sensors and data filters. Distances are expressed for optimal conditions, such as high signal-to noise ratio with low threshold and absence of cracks in the material. Signal velocity also varies widely with different wave propagation characteristics of the various masonry constituents. AE signal velocities can range from $500 \mathrm{~m} / \mathrm{s}$ in lime mortars to $3500 \mathrm{~m} / \mathrm{s}$ in cement mortars [62] and similar variations can be expected in various types of clay bricks and natural stone blocks.

Table 1: Typical AE wave velocities and maximum source-sensor distances for various construction materials.

\begin{tabular}{|l|l|l|l|}
\hline & $\begin{array}{l}\text { ultrasonic wave } \\
\text { velocity }[\mathrm{m} / \mathrm{s}]\end{array}$ & $\begin{array}{l}\text { reported source-sensor } \\
\text { distance }[\mathrm{m}]\end{array}$ & references \\
\hline clay brick masonry & $500-2000$ & up to 0.8 & {$[12,63]$} \\
\hline concrete & $2500-4000$ & up to 3.0 & {$[64-66]$} \\
\hline steel & $4000-5500$ & up to 4.0 & {$[3,67]$} \\
\hline
\end{tabular}

Using $A E$ technique, the position of defects can be located by making use of a multiplicity of sensors and source location techniques such as triangulation, prior to assessing the damage progress and fracture type [68-71]. Locating acoustic emission sources in masonry is hindered by the orthotropic layout of the bricks and mortar layers, giving cause to different propagation velocity of the elastic wave in different directions. Secondly, the high wave attenuation of the porous material reduces the maximum source-sensor distance. Generally, AE wave velocities are higher in bricks and blocks than in mortar joints and brick-mortar interfaces act as reflecting surfaces. The presence of cracks and voids further hinder the propagation of the AE signal. AE source location based on simple triangulation technique is therefore not straightforward in masonry and source location is often carried out by considering the position of the sensor that firstly detected the $A E$ hit, as detection ranges are relatively low. Therefore, detection range analysis is recommended for each sensor during site monitoring.

Livitsanos et al. [72] demonstrated that taking orthotropic wave velocity into account increases the accuracy of AE source location for the triangulation technique in masonry. For masonry with solid clay bricks and lime-cement mortar under compression, crushing of the middle mortar joint is properly located with the orthotropic wave velocity scheme (see Figure 5b). By means of pencil 
lead breaks, wave velocity along the bed joints was found to be almost double the velocity perpendicular to the bed joints.

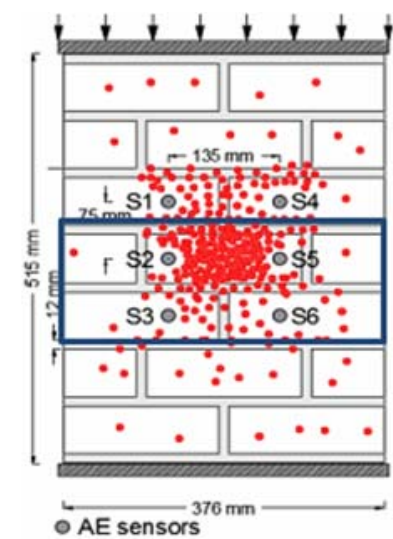

(a)

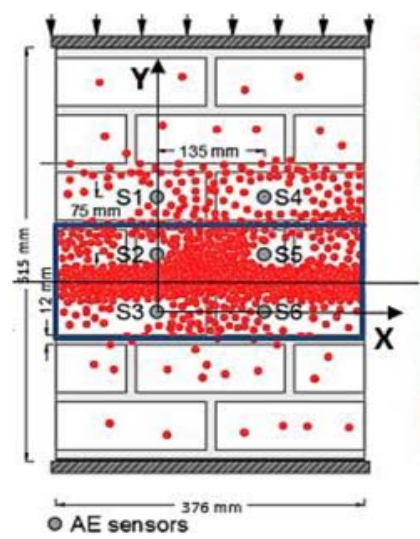

(b)

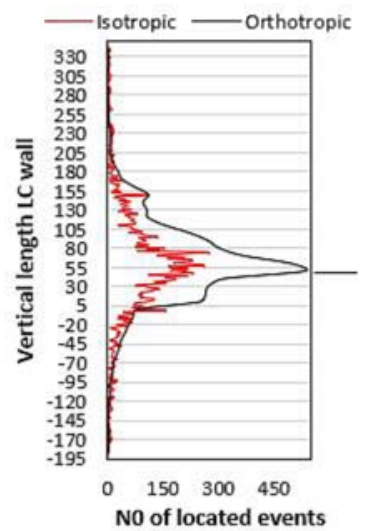

(c)

Figure 5: Result of planar AE source location with (a) isotropic and (b) orthotropic wave velocity distributions (red dots indicate located sources), (c) distribution of located AE events along the height of the masonry sample. Figures adopted from [72].

\subsection{Creep and fatigue monitoring}

Fatigue and creep are both time-dependent progressive deterioration phenomena, the former under long-term cyclic loading while the latter occurs under constant loading. Compressive creep under high sustained stresses has been identified as a potential cause of damage for masonry $[13,73]$ and the cause for collapses of several historical towers $[73,74]$. Fatigue may be relevant, for example to masonry arch bridges or to tall structures subject to wind loading. Acoustic emission has been used for studying fatigue deterioration in masonry by Melbourne and Tomor [14], De Santis and Tomor [63] and Masera et al. [50] under laboratory conditions, and by Tomor and Melbourne [75], Shigeishi et al. [76] and Invernizzi et al. [77] on vaults and masonry arch bridges. Acoustic emission monitoring has been used to study creep deterioration in masonry by Verstrynge et al. [11, 12] and by Carpinteri and Lacidogna [16]. During accelerated creep tests, $\mathrm{AE}$ monitoring can also help to determine the rate of stress increase as demonstrated on sandstone samples by Verstrynge et al. [59].

Both for creep and fatigue, damage development occurs as a three-stage process. The primary phase (damage initiation) is marked by decreasing damage rate, the secondary phase (crack propagation) by constant damage rate and the tertiary phase (failure) by coalescence of microcracks and damage accumulation. Deterioration can be monitored through strain, deformation or AE activity. Figure 6 indicates good agreement between a theoretical three-phased creep curve and cumulative $A E$ events during uniaxial compressive creep tests of masonry samples [78]. 
A relation can be sought between AE activity during the secondary creep/fatigue phase (phase $B$ in Figure 6) and time/amount of cycles to failure. In Section 2, this approach was referred to as event counting. The $A E$ activity is hereby expressed in terms of the $A E$ event rate or $A E$ energy rate, which is the derivative of the curves presented in Figure 6 and has a "bathtub shape" with Weibull-type statistical distribution [12].
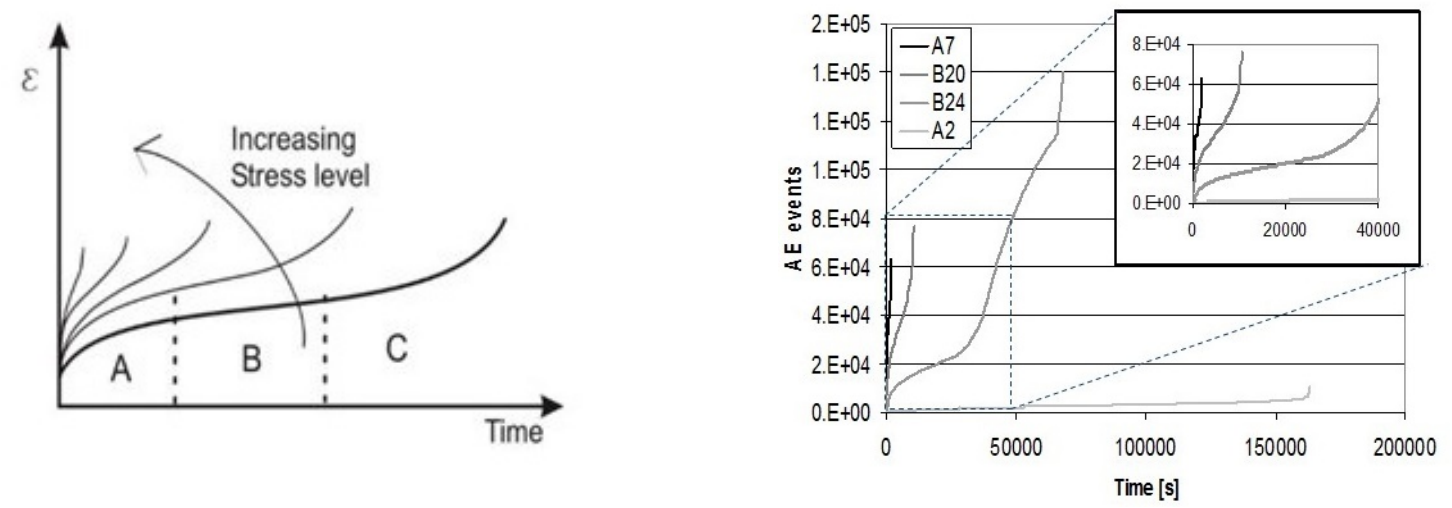

Figure 6: Comparison between a theoretical creep curve on the left (strain as a function of time) and cumulative $A E$ events as a function of time from uniaxial compressive creep tests on four masonry samples on the right. Figure adopted from Verstrynge [11].

\subsubsection{AE monitoring of creep deterioration rate}

$A E$ monitoring was used to study the rate of deterioration during the secondary creep phase for various stress levels, quantified as number of $A E$ events per minute against time to failure for small-scale masonry samples as shown in Figure 7 [8, 12]. There is a clear correlation between the $A E$ event rate and time to failure, although values are presented on a double logarithmic scale with decreasing accuracy for increasing failure time. Accuracy may also be reduced for lower stress levels with longer times to failure if the $A E$ activity is of similar magnitude to the background noise. Although values in Figure 7 are for specific masonry types and AE setup under constant environmental conditions, it demonstrates the use of $A E$ monitoring for creep failure predictions. For details on the samples and test setup, the reader is referred to $[8,78]$. 


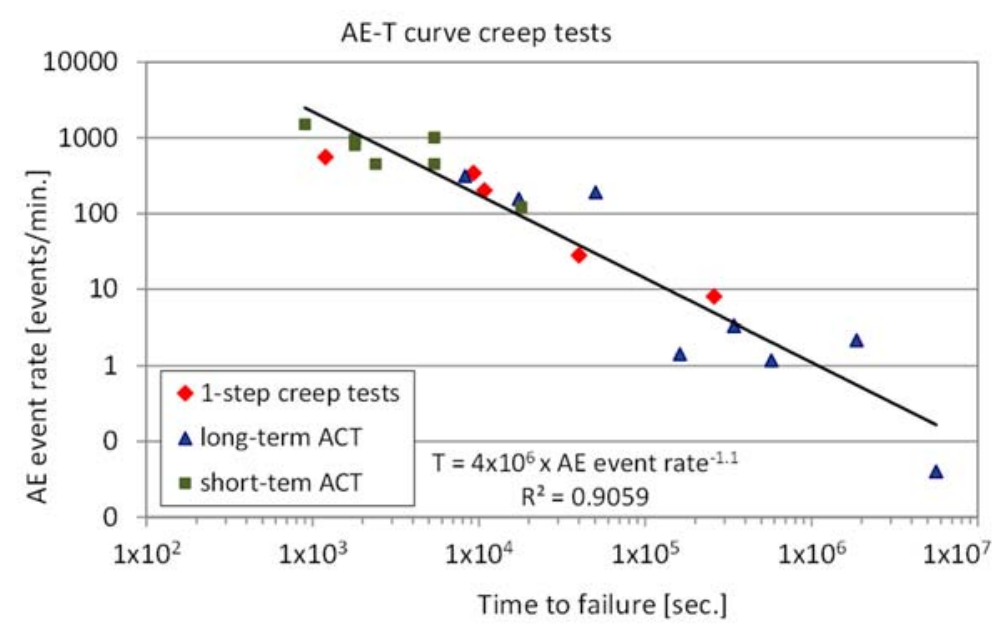

Figure 7: Correlation between AE event rate and time to failure during the secondary creep phase of masonry samples under uniaxial compressive creep loading in an accelerated creep test (ACT). Figure adopted from Tomor and Verstrynge [8].

\subsubsection{Periodic monitoring during long-term creep tests}

During long-term step-wise creep tests, the applicability of the acoustic emission technique for monitoring creep progress with discontinuous, periodic measurements was investigated. This gives an indication of the potential for periodic site monitoring in case of suspected creep damage in masonry. Masonry samples were constructed with clay bricks and lime mortar, with A-type specimens being allowed to carbonate naturally and B-type specimens being subjected to accelerated carbonation. For a detailed description of the sample preparation and test setup, the reader is referred to $[11,78]$.

During long-term step-wise creep tests, a start load of $40-50 \%$ of the average compressive strength was applied, and loads were subsequently increased in steps of 5-10 \% every 2 months. The average AE event rates, detected during a period of 24 hours in the middle of each constant load interval (one month after the stress increase step) are indicated in Figure 8. They are presented for subsequent steps for a set of five samples, up to the previous to last loading step. This means that the step after the last stress increase, in which the specimen fails, is not included.

Low $A E$ event rate is detected during the successive constant load steps. Significant increase in the $A E$ event rates was observed by specimens $B 1, B 3, A 1$ and $A 2$ during the last measurement. Although remarkably higher than the other measurements, these AE event rates are not critical, which is confirmed by the fact that the specimens did not fail until another stress increase step was imposed. Specimen B2 did not display increased activity and failure could not be predicted from the AE recordings. No AE measurement was performed at step 8 due to technical issues. From these observations, it can be remarked that periodic $A E$ monitoring could predict the failure of four out of five specimens even in the load step before the last load increment. Increase in $A E$ 
activity in step 3 was caused by temporary increase in relative humidity in the laboratory and indicates that $A E$ monitoring is sensitive enough to record internal changes caused by environmental conditions (e.g. humidity, temperature). This should be kept in mind during site monitoring.

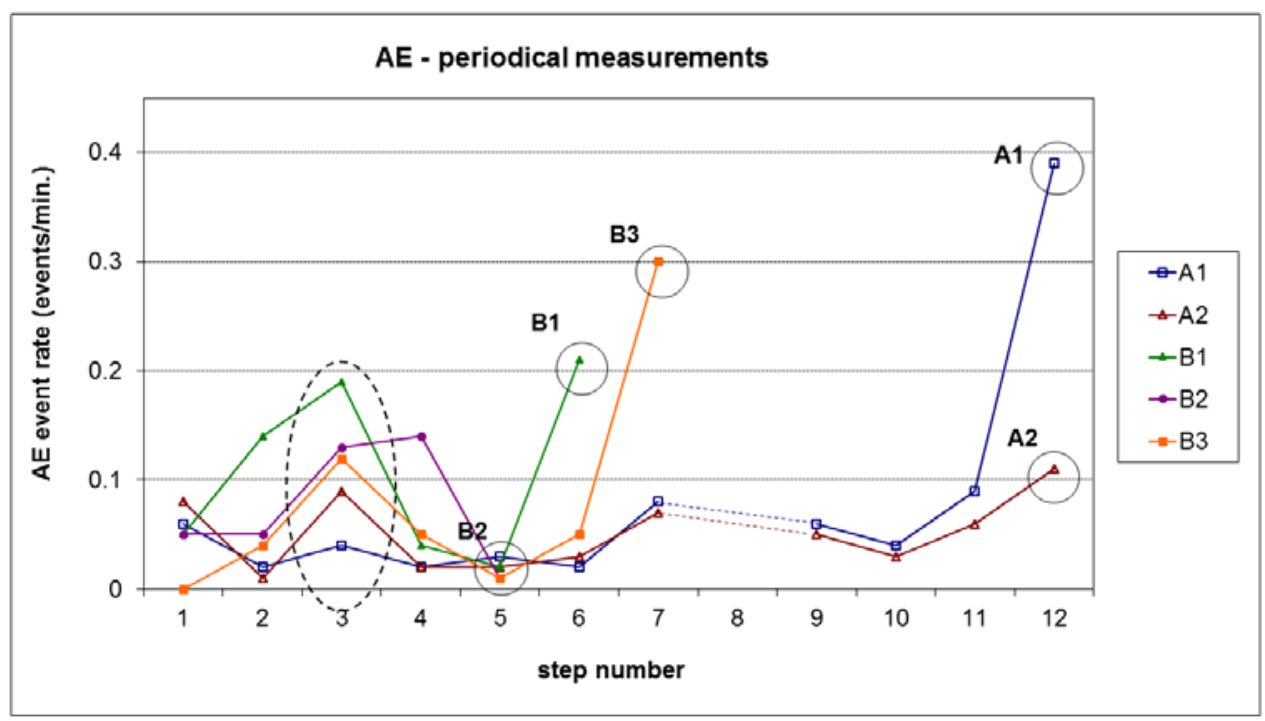

Figure 8: AE event rates monitored from periodic measurements during long-term accelerated compressive creep tests on masonry [11].

\section{Site monitoring of masonry structures}

During site monitoring, active or passive AE monitoring can be applied. In the former, a load is actively applied that is higher than service loads, e.g. test loading on bridges $[63,79]$ or flat jack tests in masonry [80]. Passive AE monitoring relies on $A E$ activity produced during in-service conditions, such as friction-related AE activity in existing cracks, or fracture progress from timedependent degradation processes. Some of the first site applications for monitoring crack activity in historical masonry buildings were reported by Carpinteri et al. [16] on an 18th century masonry building and on a number of historical masonry towers. Active AE monitoring was performed during a full-scale loading test of a historical masonry vault [27]. Shigeishi et al. [76] applied AE monitoring on a masonry and concrete bridge. AE energy was found to be much lower in masonry than in concrete elements. AE monitoring was used during load testing of a masonry arch bridge before and after strengthening works by De Santis and Tomor [63]. The following sections will discuss the application of $A E$ monitoring to historical masonry buildings and masonry arch bridges. 


\subsection{Monitoring historical masonry buildings}

Over the years, the authors have acquired considerable experience in AE monitoring of historical buildings [7, 9, 16, 35, 81-85]. In this Section, a selection of case studies is briefly presented to show the capability of AE monitoring to assess damage evolution in historical masonry buildings.

For the site monitoring, "Units for Storage Acoustic emission Monitoring" (USAM) were applied that can be synchronized for multichannel data processing [86]. The most relevant parameters acquired from the $\mathrm{AE}$ signals (frequencies in a range between 50 and $800 \mathrm{kHz}$, arrival time, amplitude, duration, number of events and oscillations) were stored in the USAM memory and downloaded to a PC for further processing.

\subsubsection{Monitoring crack propagation and crack stability}

AE technique was used for monitoring a historical masonry building (Casa Capello in the City of Rivoli near Turin in Italy) following sudden collapse of a downhill breast wall [7]. The wall was rebuilt shortly after the incident and the soil under the wall was strengthened. A diffused network of cracks however started to form in the original parts of the building shortly after the repair works. Two noticeable horizontal cracks appeared in the basement walls, about $1.8 \mathrm{~m}$ above the floor, and propagated slowly, enabling to monitor their progress with the acoustic emission technique, using a method referred to as "event counting" in Section 2.

Two AE sensors were located about $30 \mathrm{~mm}$ from each crack tip and crack development was monitored for about 900 hours for crack no. 1 and for 800 hours for crack no. 2. Cumulative counting of AE events, count rate and crack propagation are shown in Figure 9 as average values for the two AE transducers positioned at each crack tip. There is strong correlation between $\mathrm{AE}$ count and crack propagation. Reduction in the count rate over time indicated the slowdown and arrest of crack propagation as the cracks progressed towards a more highly compressed section of the wall. The average velocity of crack propagation was ca. $0.04 \mathrm{~mm} / \mathrm{h}$ for crack no. 1 and 0.17 $\mathrm{mm} / \mathrm{h}$ for crack no. 2. The effectiveness of the AE monitoring was due to the fact that the cracks evolved slowly and developed in an area very close to the AE sensors. AE monitoring was therefore able to identify the rate of crack propagation and the onset of a new stability condition. 


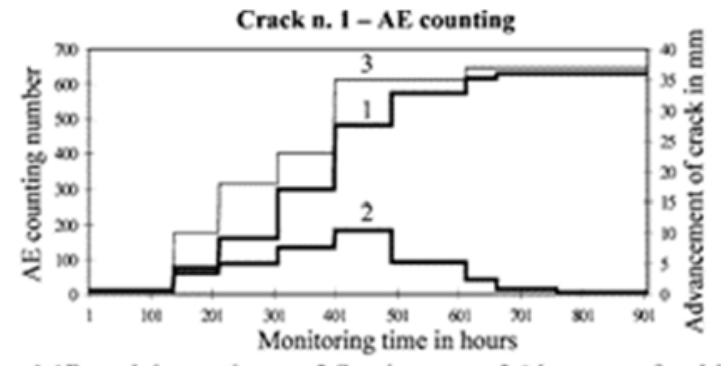

(a)

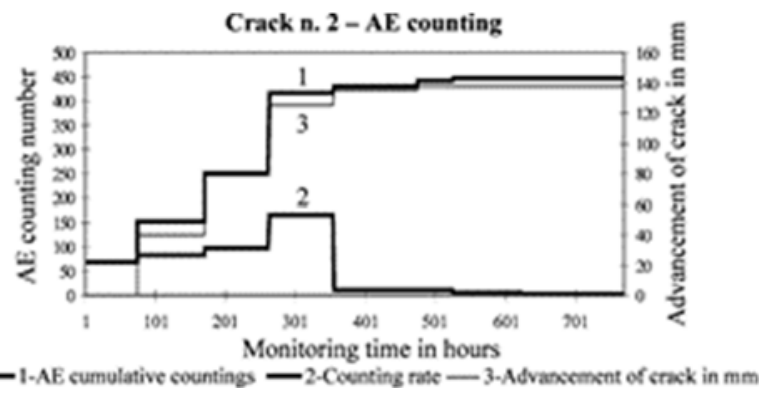

(b)

Figure 9: Cumulative counting of $A E$ events, count rate and crack propagation in $\mathrm{mm}$ against time for cracks a) no. 1 and b) no. 2. Figures from Carpinteri and Lacidogna [7].

AE technique was also used to monitor the stability of three medieval towers, Torre Sineo, Torre Astesiano and Torre Bonino in the City of Alba also near Turin in Italy (Figure 10) by estimating the energy emitted during the crack propagation [16].

The Sineo tower had a range of vertical cracks near openings and two cracks were detected using $\mathrm{AE}$ monitoring in the inner masonry layer at the seventh floor. Monitoring revealed slow internal crack propagation inside the brick walls. Crack development had stopped in the area of highest damage as the building developed a new state of structural stability.

The Astesiano Tower had a long vertical crack in the upper part of the southern façade and was monitored near the tip of the crack on the inner masonry leaf at the fourth floor. The cumulative number of AE counts evolved progressively over time. A seismic event of magnitude 4.7 on the Richter scale occurred during the monitoring period after which an increase of $A E$ counts was observed.

In the Torre Bonino, blocked up openings and passageways were revealed by a survey at various floor levels, linking the tower to the adjacent. The historical openings caused significant reduction in the load bearing capacity of the tower. The tower was monitored at first floor level, where the effects of the openings and dead weight was the most critical and AE identified active creep deterioration. 


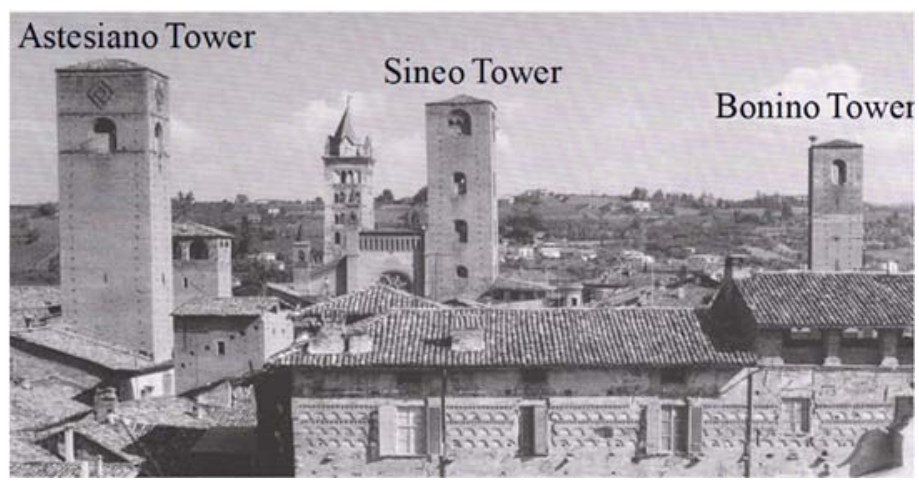

Figure 10: Three medieval towers rising in the center of Alba, that were investigated with $A E$ monitoring. Figure adapted from [16].

As the three towers are very near each other (Figure 10), the impact of earthquakes on damage evolution was assessed for all the towers [9], and it was found that during the observation period, the towers behaved as sensitive earthquake receptors. For more information on the structural assessment of the towers, the reader is referred to [16] for a general overview, and to [87] for a detailed description of the correlation between $A E$ recordings in the towers and earthquake events.

\subsubsection{Monitoring cracks and delamination in historic frescoes}

The preservation of historic frescoes is a complex problem that requires the use of nondestructive investigation methods to assess the integrity of vulnerable tangible heritage without affecting its state of conservation [88]. AE technique was used for monitoring historic frescoes in the Monte Tabor Chapel, in the UNESCO Renaissance Complex of the Sacred Mountain of Varallo in Piedmont by Carpinteri et al [17]. Six USAM AE sensors were used to monitor the damage evolution of the structure and the decorated surfaces of the Chapel. Four AE sensors were positioned around a vertical crack and two near a detached area (Figure 11). Attaching the sensors was a sensitive issue and was carried out by restorers. A film of Japanese paper coated with an acrylic resin was used to form a protective base for the AE sensors, bonded to it with silicone glue. 


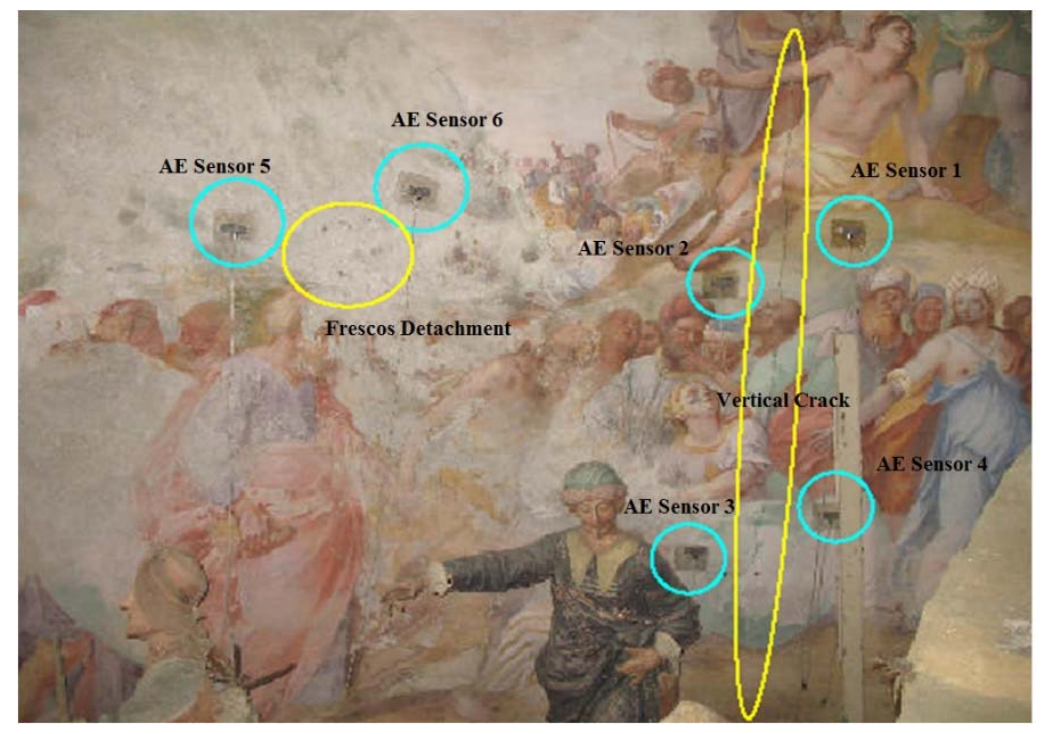

Figure 11: View of the monitored damage zones and position of the AE sensors. Reprint from [17] under Creative Commons Attribution License, https://creativecommons.org/licenses/by/3.0/

AE data analysis included cumulative AE events, frequency and $b$-values, as discussed in Section 2.2. Results indicated that the vertical crack presented a stable condition during the acquisition period with relatively low frequency signals $(<200 \mathrm{kHz})$ and a $b$-value in the range $0.95-1.15$. In this case, it is interesting to note that, since the monitored wall is of large dimensions, a $b$-value approaching 1 does not imply a substantial loss of load-bearing capacity of the entire wall, but rather the coalescence of micro-cracks along the vertical crack (see also Figure 3 in Section 2.2), which can continue to advance without substantially compromising the stability of the structure. The fresco detachment tended to evolve towards metastable conditions and the signals acquired showed high frequency characteristics $(<400 \mathrm{kHz})$. Therefore a distribution of micro-cracks in the volume was assumed for the analysed region. Detachment of the fresco caused by the presence of moisture in the mortar substrate was found to be gradual and cyclical.

\subsection{Monitoring masonry arch bridges}

In this section, it is shown how $A E$ technique can be applied on masonry arch bridges that represent around $40 \%$ of the European bridges. These bridges are often over 100 years old and of strategic importance for the rail and road infrastructure. For the maintenance of bridges two questions are of key interest to the engineer, i) what is the condition and capacity of the structure and ii) what vehicles/actions are causing deterioration?

Masonry bridges often have historic cracks/defects that developed over the years and do not significantly affect their capacity or rate of deterioration (e.g. longitudinal cracks on the intrados at mid-width). For these defects periodic assessment or monitoring is sufficient, generally using 
visual observation or simple crack measurement. Other cracks (e.g. ring separation or vertical cracks in piers) can be more critical and their causes should be established and addressed in the short to medium-term. For identifying vehicles/actions that are causing deterioration in bridges, only a more limited range of monitoring techniques are available, for example crack/deflection measurement, dynamic monitoring and acoustic emission monitoring [89].

Acoustic emission monitoring can be used for identifying the condition of masonry arch bridges $[14,76,90,91]$, fatigue deterioration [63, 75] and scour in piers [77]. The structural behaviour of a masonry arch is strongly affected by crack formation and stress redistribution following the repositioning of the line of thrust [92]. Accurate information on structural condition can help suitable assessment methods to be selected, for example using elastic theory, incremental approach (taking gradual fracture developments into account) or limit analysis.

To provide an overview of the key features of AE monitoring of masonry arch bridges, two case studies have been selected: one railway and one road brickwork arch bridge. For field monitoring the first step is to establish a suitable sensor arrangement for the limited number of available sensors. The location and density of $A E$ sensors are limited by signal attenuation. In brickwork, the amplitude of $A E$ signal generally reduces below $50 \mathrm{~dB}_{\mathrm{AE}}$ within ca. five bricks distance (see Table 1). Hence, AE source location is determined from sensor locations as discussed in Section 3.1. Sensors can first be placed evenly along the intrados and spandrel walls (within 10 brick distance for a row of sensors) to identify regions with high emission ( $>60 \mathrm{~dB}_{\mathrm{AE}}$ ) and subsequently moved to regions with high emission to identify the nature of damage and types of loading causing deterioration.

\subsubsection{Locating damage and causes of deterioration}

To demonstrate the efficacy of AE monitoring for condition assessment of masonry arch bridges, a $3.6 \mathrm{~m}$ span stone arch bridge was monitored under railway loading (Figure 12) [93]. Traffic included light passenger trains and freight trains up to 25.4 tonnes axle weight. The brickwork was in good condition, but three longitudinal cracks were visible on the arch intrados (at the middle of the arch barrel and alongside each spandrel wall). Six acoustic emission sensors (AE16 ) were attached to the intrados using hot melt glue under the tracks. Installation of the sensors and monitoring system took approximately 30 minutes. 


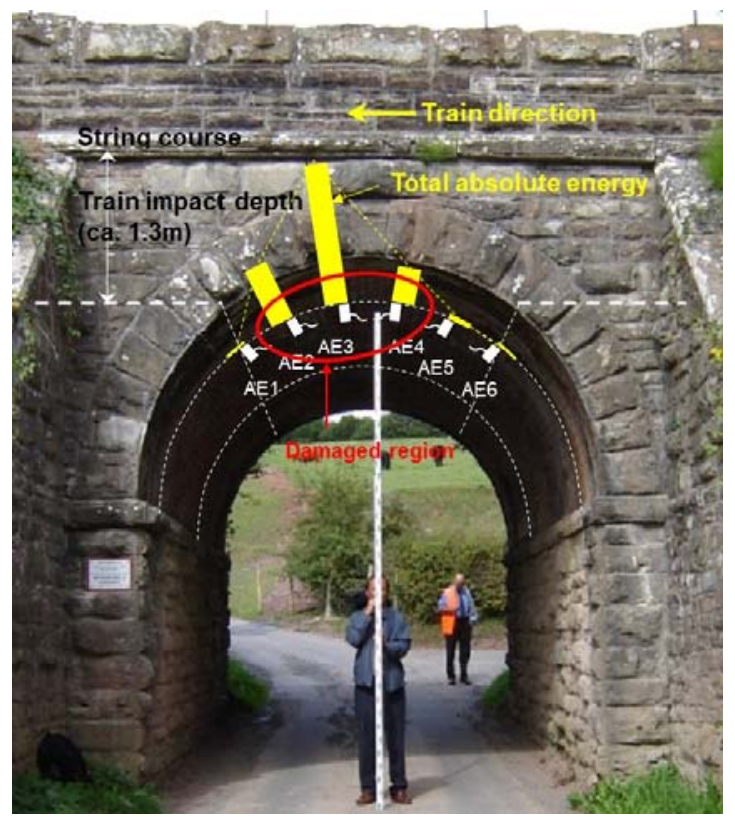

Figure 12: Arch bridge with AE sensor locations

AE recordings for a light passenger train (3 carriages, ca. 12 tonnes/axle) (Figure 13) show low amplitude emissions $\left(<40 \mathrm{~dB}_{\mathrm{AE}}\right)$ and indicate no significant damage. AE recordings under a heavy freight train (10 wagons, ca. 22 tonnes/axle) (Figure 13) however show significant emission $(<60$ $\mathrm{dB}_{\mathrm{AE}}$ ) near the top of the arch by sensors AE3-5 and indicate that freight trains are likely to cause fatigue damage to the bridge. $\mathrm{AE}$ hits correspond to the relevant train carriages/bogies in the time domain.

As another useful indicator, critical areas of damage can be visualised using the total absolute energy for each sensor as shown in yellow in Figure 12. The greatest accumulated absolute energy was recorded by sensors AE2, AE3, AE4 near the crown. Greatest damage occurs to the left of the crown (near AE4) as the train is approaching from right and the arch is pushed against the backfill to the left. Traffic loading is actively 'felt' by the arch down to ca. $1.3 \mathrm{~m}$ from the string-course and fatigue deterioration is likely to be caused by freight trains. 


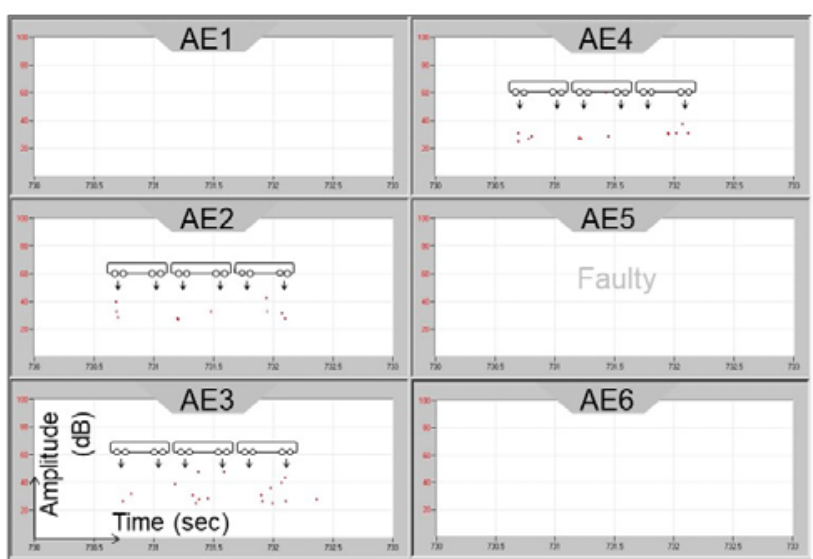

a) Light passenger train

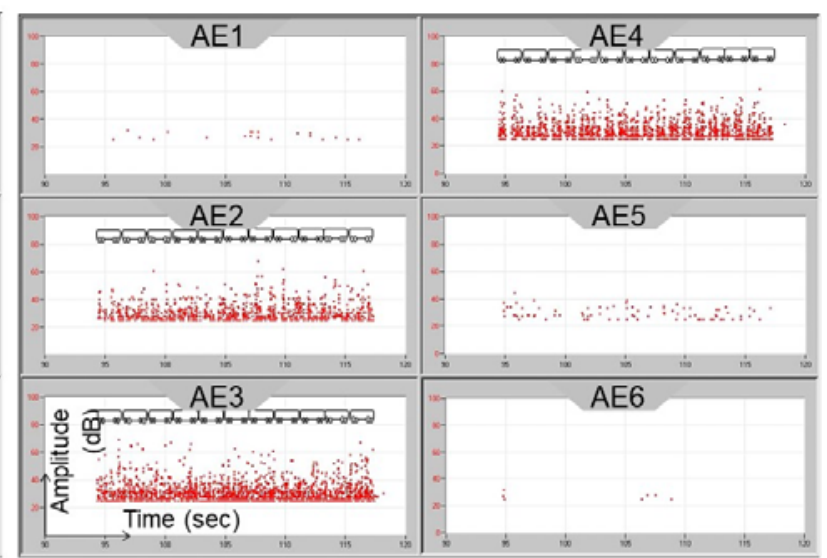

b) Heavy freight train

Figure 13: Amplitude vs. time under a) light passenger train and b) heavy freight train

\subsubsection{Identifying efficacy of refurbishment works}

A $22 \mathrm{~m}$ span multi-ring brickwork road arch bridge (Figure 14) was monitored under controlled loading before and after refurbishment works took place. A number of cracks were visible in the structure as shown in Figure 14. Eight permanent acoustic emission sensors (AE1-8) were attached to the spandrel wall and the intrados next to existing cracks. Installation of the permanent monitoring system took ca. 4 hours.

Controlled load tests were carried out using a $32 \mathrm{t}$ lorry driving over the bridge at different speeds $(5,15,30 \mathrm{mph})$. Before strengthening, $A E$ amplitude was proportional to the vehicle speed with maximum amplitude around $80 \mathrm{~dB}_{\mathrm{AE}}$ at $30 \mathrm{mph}$, as shown (in yellow) in Figure 14. The largest activity recorded by sensors AE2 and AE4 was caused by the opening and closing of hinges and possibly crushing of bricks. Sensor AE1 indicated sliding/grinding between the rings and sensor AE7 indicated movement in the internal spandrel walls on the intrados. Areas of critical activity were therefore identified near the hinges, ring separation, string course and on the intrados.

After refurbishment the controlled load tests with a $32 \mathrm{t}$ lorry were repeated and results included (in blue) in Figure 14. Emission was significantly reduced to background noise $\left(<30 \mathrm{~dB}_{\mathrm{AE}}\right.$ ) for most of the sensors. The only notable activity was around AE2 but was also significantly reduced, indicating that the radial hinge was still active but grinding/crushing reduced due to the introduction of a soft contact membrane at the hinge. Reduced emission indicated that grouting and radial pinning effectively reinstated the structure. 


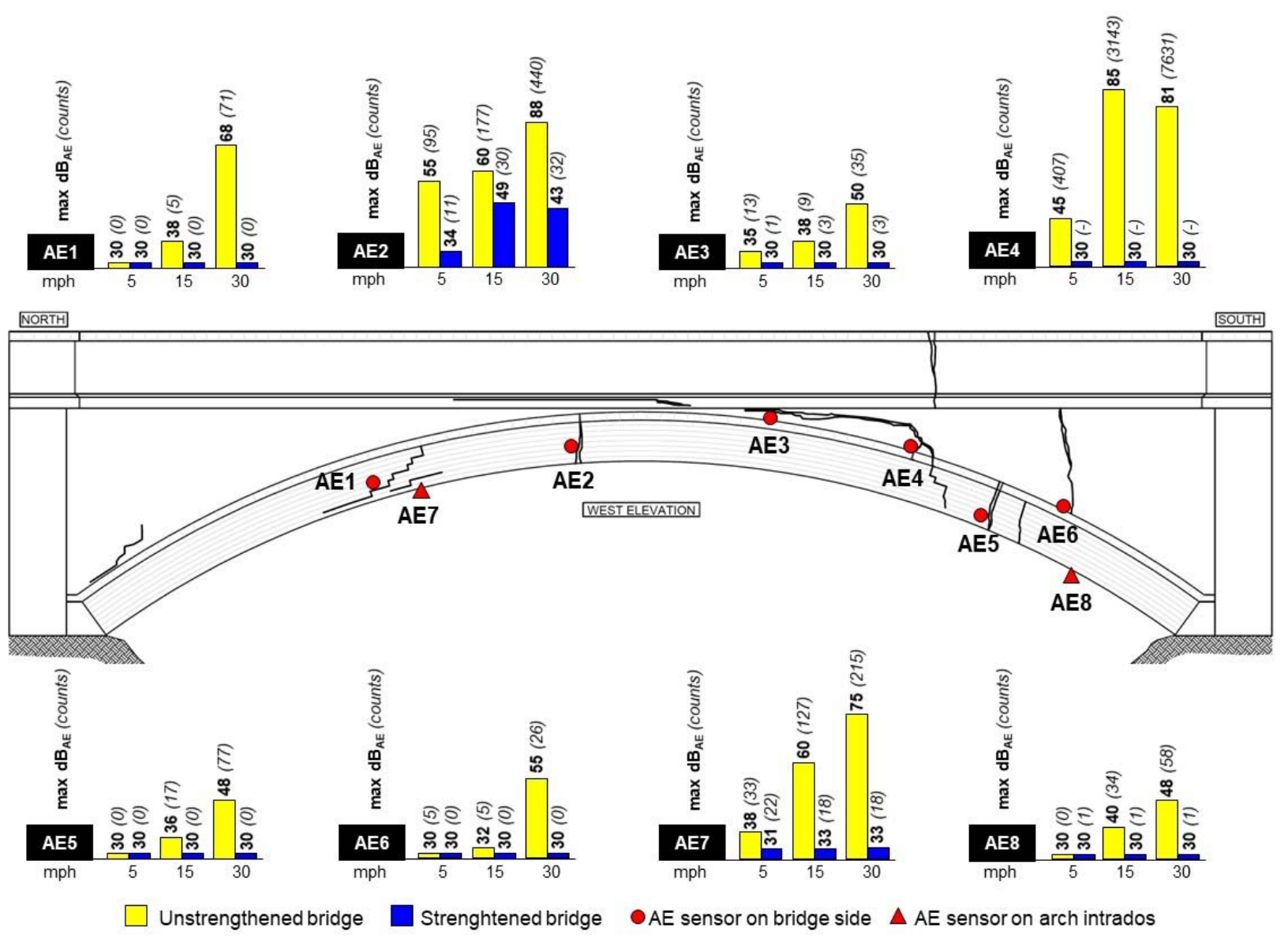

Figure 14: Crack pattern, location of AE sensors, maximum AE amplitude and counts during controlled load tests before and after strengthening at different lorry speeds [63].

After refurbishment, the bridge was monitored for 8 hours under normal traffic loading. Emission level was below the critical limit of $60 \mathrm{~dB}_{\mathrm{AE}}$ for all sensors and mostly below $40 \mathrm{~dB}_{\mathrm{AE}}$ (Figure 15). Grinding and crushing in existing cracks was therefore reduced or eliminated by the repair works. Emission around $50 \mathrm{~dB}_{\mathrm{AE}}$ at $\mathrm{AE} 2$ was associated with lorries passing over the bridge, indicating that the nearby hinge is still active and allows flexibility of the (otherwise stiff) arch.

Monitoring can be repeated in future and compared with previous readings. If amplitudes increase over $60 \mathrm{~dB}_{\mathrm{AE}}$ more investigation will be necessary to identify the origin and nature of damage. AE monitoring can therefore be useful to identify areas of damage, causes of damage and changes in structural condition over time. 


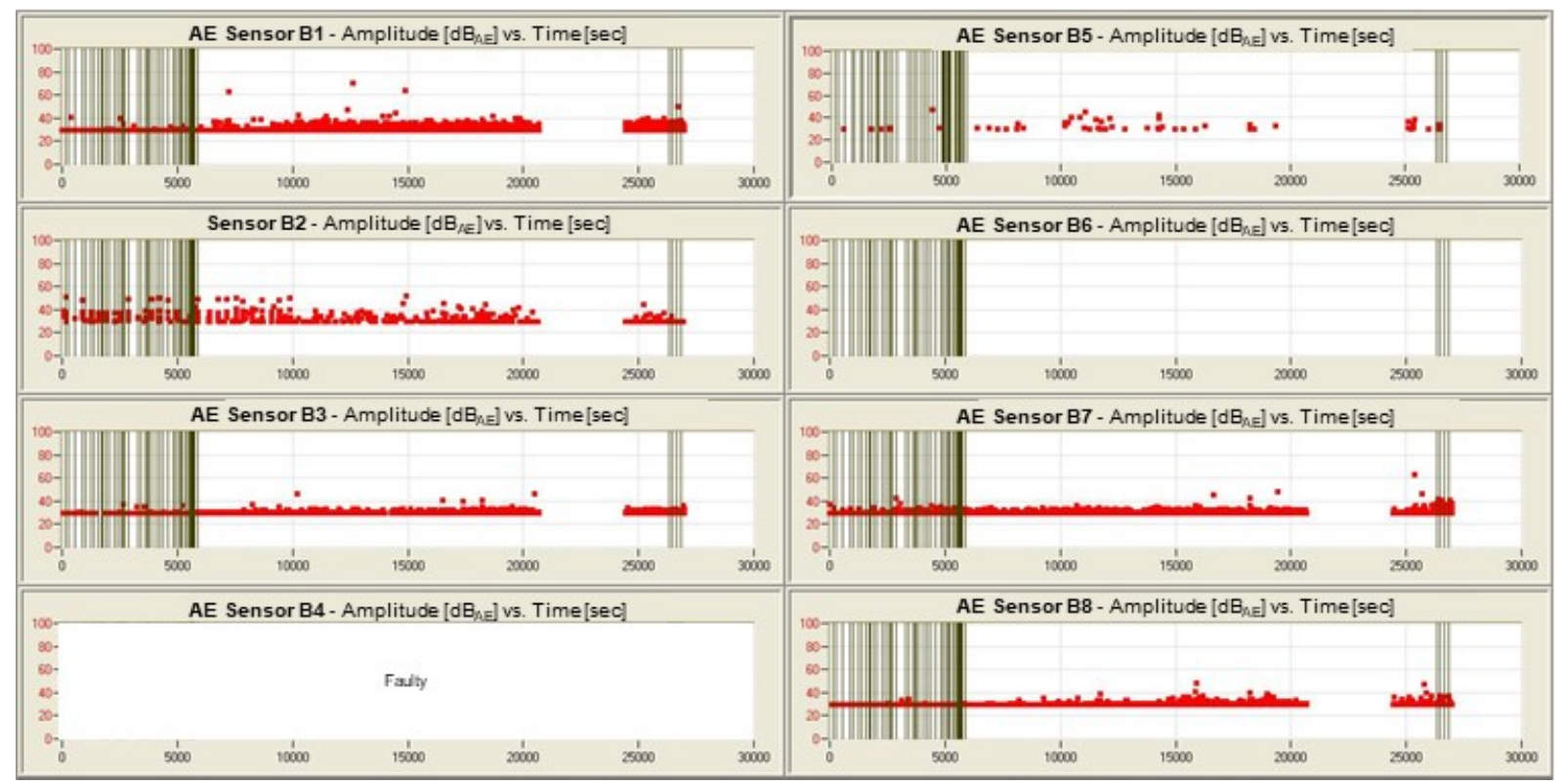

Figure 15: AE recording during 8-h monitoring under normal traffic: amplitude vs. time (screen shot of the acquisition software) [63].

\section{Conclusions and future challenges}

The non-invasive nature and high sensitivity of acoustic emission ( $A E$ ) technique offers a useful research and application tool for monitoring masonry structures. To provide a solid base for further developments and enhance the application of AE sensing in masonry, this review paper provides an elaborate literature overview on damage detection in masonry structures with the acoustic emission technique. AE-based monitoring approaches are discussed for masonry, such as $A E$ event counting, parameter analysis, $b$-value and simplified signal-based analysis. It was shown that the application of $A E$ methods that are standardized for concrete testing require adjustments when used for masonry. Damage limits established for LOAD-CALM analysis in concrete are too conservative for masonry. Simplified waveform-based approaches (e.g. RA-AF analysis) need be used with care for masonry as distortion of the waveform properties increases with increasing source-sensor distance and number of mortar joint crossings. Further, it was also shown how an orthotropic wave velocity distribution largely increases the AE source location accuracy in masonry.

Three-phase micro-fracture development under fatigue and creep loading was discussed for laboratory experiments, together with $A E$ event rate for secondary and tertiary phases. A correlation between $A E$ event rate and time to failure was presented. Indications of the applicability of acoustic emission technique for on-site monitoring were given by a discussion of AE data from periodic measurements. 
Site monitoring of historical towers, buildings and masonry bridges demonstrated practical application of the system and AE-based damage assessment methods. AE counts were correlated with crack propagation and changes in rate of crack development were identified. Monitoring the condition and deterioration processes of wall paintings was demonstrated through identifying stable crack growth and gradual detachment of a fresco due to cyclic changes in moisture content in the mortar substrate. Critical areas of damage were identified in masonry arch bridges and causes of fatigue deterioration were linked to vehicle types. Load testing also showed to be and effective tool to identify the behaviour of the structure before and after refurbishment and the efficacy of refurbishment works.

Future challenges are mostly related to the heterogeneity of masonry and rapid wave attenuation compared to the large size of masonry structures. Orthotropic wave propagation velocities and correction of waveform properties for longer source-sensor distances have been highlighted as potential tools to address these issues. Further research is required to develop source location and waveform correction algorithms for various masonry types. In addition, research investigations should aim at adjusting standardized AE methods for concrete towards applications on masonry.

For site monitoring, the development of high-sensitivity, robust and integrated AE sensors would pose a major step forward. Current advances in this area are made with fibre optics and multifrequency spectrum sensors. Most site monitoring focusses on one specific deterioration phenomenon or places the sensors in the vicinity of active crack locations to ensure a good correlation between AE data and the damage mechanism. Dedicated filtering tools and multisensor networks would improve the monitoring potential for multiple damage mechanisms (e.g. creep and salt efflorescence) and applications in noisy environments (e.g. bridges).

\section{Acknowledgements}

The authors gratefully acknowledge financial support by the Research Foundation - Flanders (FWO) (grant numbers G0C3815N, G088920N and 12D1512N) and The Engineering and Physical Sciences Research Council (EPSRC) (grant number EP/F069170/1).

\section{References}

[1] Wevers M. Listening to the sound of materials: Acoustic emission for the analysis of material behaviour. NDT \& E International 1997; 30(2):99-106.

[2] Grosse C.U., Ohtsu M., eds. Acoustic emission testing - basics for research - applications in civil engineering. Springer. (2008).

[3] Aggelis D.G., Matikas T.E. Effect of plate wave dispersion on the acoustic emission parameters in metals. Computers \& Structures 2012; 98-99:17-22. 
[4] Lura P., Couch J., Jensen O.M., Weiss J. Early-age acoustic emission measurements in hydrating cement paste: Evidence for cavitation during solidification due to self-desiccation. Cement and Concrete Research 2009; 39(10):861-867.

[5] Dzaye E.D., De Schutter G., Aggelis D.G. Study on mechanical acoustic emission sources in fresh concrete. Archives of Civil and Mechanical Engineering 2018; 18(3):742-754.

[6] Shiotani T., Fujii K., Aoki T., Amou K. Evaluation of progressive failure using AE sources and improved b-value on slope model tests. Progress in Acoustic Emission 1994; 7:529-534.

[7] Carpinteri A., Lacidogna G. Damage Monitoring of an Historical Masonry Building by the Acoustic Emission Technique. Materials and Structures 2006; 39(2):161-167.

[8] Tomor A.K., Verstrynge E. A joint fatigue-creep deterioration model for masonry with acoustic emission based damage assessment. Construction and Building Materials 2013; 43:575-588.

[9] Carpinteri A., Lacidogna G. Structural monitoring and integrity assessment of medieval towers. Journal of Structural Engineering (ASCE) 2006; 132:1681-1690.

[10] Behnia A., Chai H.K., Shiotani T. Advanced structural health monitoring of concrete structures with the aid of acoustic emission. Construction and Building Materials 2014; 65:282-302.

[11] Verstrynge E. Chapter 11: Acoustic Emission testing, in Long-term Performance and Durability of Masonry Structures - Degradation Mechanisms, Health Monitoring and Service Life Design Ghiassi B., Lourenço P.B., Editors. Elsevier, Woodhead Publishing. 2019. p.

[12] Verstrynge E., Schueremans L., Van Gemert D., Wevers M. Monitoring and predicting masonry's creep failure with the acoustic emission technique. NDT \& E International 2009; 42(6):518-523.

[13] Verstrynge E., Van Gemert D. Creep failure of two historical masonry towers: analysis from material to structure. International Journal of Masonry Research and Innovation 2018; 3(1):5071.

[14] Melbourne C., Tomor A.K. Application of acoustic emission for masonry arch bridges. Strain 2006; 42(3):165-172.

[15] Alexakis H., Liu H., DeJong M.J. Damage identification of brick masonry under cyclic loading based on acoustic emissions. Engineering Structures 2020; 221:110945.

[16] Carpinteri A., Lacidogna G. Damage evaluation of three masonry towers by acoustic emission. Engineering Structures 2007; 29(7):1569-1579.

[17] Carpinteri A., Lacidogna G., Invernizzi S., Accornero F. The Sacred Mountain of Varallo in Italy: Seismic Risk Assessment by Acoustic Emission and Structural Numerical Models. The Scientific World Journal 2013; 2013:10.

[18] Verstrynge E., De Wilder K., Drougkas A., Voet E., Van Balen K., Wevers M. Crack monitoring in historical masonry with distributed strain and acoustic emission sensing techniques.

Construction and Building Materials 2018; 162:898-907.

[19] Verstrynge E., Wevers M. Initial results on acoustic emission detection in masonry with optical fibre sensors in 30th European Conference on Acoustic Emission Testing / 7th International Conference on Acoustic Emission, NDT.net, Editor: Granada. 2012.

[20] Verstrynge E., Pfeiffer H., Wevers M. A novel technique for acoustic emission monitoring in civil structures with global fiber optic sensors. Smart Materials and Structures 2014; 23(6):065022.

[21] Ohtsu M. Innovative AE and NDT Techniques for On-Site Measurement of Concrete and Masonry Structures. State-of-the-Art Report of the RILEM Technical Committee 239-MCM. 2016.

[22] Ishibashi A., Matsuyama K., Alver N., Suzuki T., Ohtsu M. Round-robin tests on damage evaluation of concrete based on the concept of acoustic emission rates. Materials and Structures 2015:1-9.

[23] Grossi C.M., Esbert R.M., delRio L.M.S., Montoto M., LaurenziTabasso M. Acoustic emission monitoring to study sodium sulphate crystallization in monumental porous carbonate stones. Studies in Conservation 1997; 42(2):115-125. 
[24] Andreev K., Shetty N., Verstrynge E. Acoustic emission based damage limits and their correlation with fatigue resistance of refractory masonry. Construction and Building Materials 2018; 165:639-646.

[25] Recommendation of RILEM TC 212-ACD: acoustic emission and related NDE techniques for crack detection and damage evaluation in concrete. Materials and Structures 2010; 43(9):1183-1186.

[26] ISO 16837:2019: Non-destructive testing - Acoustic emission testing - Test method for damage qualification of reinforced concrete beams

[27] Carpinteri A., Invernizzi S., Lacidogna G. Structural Assessment of a 17th-Century Masonry Vault with Acoustic Emissions and Numerical Techniques. International Journal of Architectural Heritage 2007; 1(2):214-226.

[28] Shetty N., Livitsanos G., Van Roy N., Aggelis D.G., Van Hemelrijck D., Wevers M., et al. Quantification of progressive structural integrity loss in masonry with Acoustic Emission-based damage classification. Construction and Building Materials 2019; 194:192-204.

[29] De Smedt M., Andreev K., Shetty N., Verstrynge E. Effectiveness of acoustic emission parameters to monitor the crack formation in refractories - Case study on castables of different brittleness. Journal of the European Ceramic Society 2019; 39(16):5423-5432.

[30] Aggelis D.G. Classification of cracking mode in concrete by acoustic emission parameters. Mechanics Research Communications 2011; 38(3):153-157.

[31] Livitsanos G., Shetty N., Hundgen D., Verstrynge E., Wevers M., Van Hemelrijck D., et al. Acoustic emission characteristics of fracture modes in masonry materials. Construction and Building Materials 2018; 162:914-922.

[32] Carpinteri A., Lacidogna G., Accornero F., Mpalaskas A.C., Matikas T.E., Aggelis D.G. Influence of damage in the acoustic emission parameters. Cement \& Concrete Composites 2013; 44:9-16.

[33] Shiotani T., Yuyama S., Li Z.W., Ohtsu M. Quantitative evaluation of fracture processes in concrete by the use of improved b-value. Non-Destructive Testing in Civil Engineering 2000 2000:293-302.

[34] Colombo I.S., Main I.G., Forde M.C. Assessing damage of reinforced concrete beam using "bvalue" analysis of acoustic emission signals. Journal of Materials in Civil Engineering 2003; 15(3):280-286.

[35] Anzani A., Binda L., Carpinteri A., Lacidogna G., Manuello A. Evaluation of the repair on multiple leaf stone masonry by acoustic emission. Materials and Structures 2008; 41(6):1169-1189.

[36] Carpinteri A., Lacidogna G., Pugno N. Structural damage diagnosis and life-time assessment by acoustic emission monitoring. Engineering Fracture Mechanics 2007; 74(1-2):273-289.

[37] Aki A. A probabilistic synthesis of precursory phenomena. Earthquake prediction: An international review. M. Ewing Series, ed. Simpson D.W., Rlchards P.W. Vol. 4. 1981. 566-574.

[38] Lemaitre J., Chaboche J.L. Mechanics of Solid Materials: Cambridge University Press. 1990.

[39] Krajcinovic D. Damage Mechanics: Elsevier, Amsterdam. 1996.

[40] Turcotte D.L. Fractals and Chaos in Geology and Geophysics: Cambridge University Press. 1997.

[41] Carpinteri A., Accornero F. Multiple snap-back instabilities in progressive microcracking coalescence. Engineering Fracture Mechanics 2018; 187:272-281.

[42] Carpinteri A., Accornero F. The Bridged Crack Model with multiple fibers: Local instabilities, scale effects, plastic shake-down, and hysteresis. Theoretical and Applied Fracture Mechanics 2019; 104:102351.

[43] Lacidogna G., Accornero F., Carpinteri A. Influence of snap-back instabilities on Acoustic Emission damage monitoring. Engineering Fracture Mechanics 2019; 210:3-12.

[44] Carpinteri A., Lacidogna G., Corrado M., Di Battista E. Cracking and crackling in concrete-like materials: A dynamic energy balance. . Engineering Fracture Mechanics 2016; 155:130-144. 
[45] Carpinteri A., Lacidogna G., Pugno N. A fractal approach for damage detection in concrete and masonry structures by the acoustic emission technique. Acoustique et Techniques 2004; 38(3):31-37.

[46] Botvina L.R. Damage evolution on different scale levels. Physics of the Solid Earth 2011; 47:859872.

[47] Carpinteri A., Lacidogna G., Puzzi S. From criticality to final collapse: Evolution of the "b-value" from 1.5 to 1.0. Chaos Solitons \& Fractals 2009; 41(2):843-853.

[48] Carpinteri A., Lacidogna G., Accornero F. Fluctuations of 1/f Noise in Damaging Structures Analyzed by Acoustic Emission. Applied Sciences-Basel 2018; 8(9).

[49] Grosse C.U., Finck F. Quantitative evaluation of fracture processes in concrete using signal-based acoustic emission techniques. Cement and Concrete Composites 2006; 28(4):330-336.

[50] Masera D., Bocca P., Grazzini A. Frequency Analysis of Acoustic Emission Signal to Monitor Damage Evolution in Masonry Structures. 9th International Conference on Damage Assessment of Structures (Damas 2011) 2011; 305.

[51] Ohno K., Ohtsu M. Crack classification in concrete based on acoustic emission. Construction and Building Materials 2010; 24(12):2339-2346.

[52] Ohtsu M., Tomoda Y. Acoustic emission techniques for crack detection and damage evaluation, in 1st International Rilem Conference on 'on site Assessment of concrete, masonry and timber', SACoMaTiS, Binda L., Di Prisco M., Felicetti R., Editors. Rilem: Varenna. 2008. p. 191-200.

[53] Livitsanos G., Shetty N., Hündgen D., Verstrynge E., Wevers M., Van Hemelrijck D., et al. Acoustic emission characteristics of fracture modes in masonry materials (https://doi.org/10.1016/j.conbuildmat.2018.01.066). Construction and Building Materials 2018.

[54] ISO 16838:2019: Non-destructive testing - Acoustic emission testing - Test method for classification of active cracks in concrete structures.

[55] Aggelis D.G., Shiotani T., Papacharalampopoulos A., Polyzos D. The influence of propagation path on elastic waves as measured by acoustic emission parameters. Structural Health Monitoring-an International Journal 2012; 11(3):359-366.

[56] Livitsanos G., Shetty N., Verstrynge E., Wevers M., Van Hemelrijck D., aggelis D.G. Numerical simulation of wave propagation in masonry, in 24th International Acoustic Emission Symposium (IAES-24): Sapporo, Japan. 2018. p. 151-156.

[57] Aggelis D.G., Mpalaskas A.C., Ntalakas D., Matikas T.E. Effect of wave distortion on acoustic emission characterization of cementitious materials. Construction and Building Materials 2012; 35:183-190.

[58] Livitsanos G., Shetty N., Verstrynge E., Wevers M., Van Hemelrijck D., aggelis D.G. Numerical simulation of elastic wave propagation in masonry compared with acoustic emission experimental results. Archives of Civil and Mechanical Engineering 2020; 20(1):1-11.

[59] Verstrynge E., Adriaens R., Elsen J., Van Balen K. Multi-scale analysis on the influence of moisture on the mechanical behavior of ferruginous sandstone. Construction and Building Materials 2014; 54:78-90.

[60] Andreev K., Shetty N., de Smedt M., Yin Y., Verstrynge E. Correlation of damage after first cycle with overall fatigue resistance o refractory castable concrete. Construction and Building Materials 2019; 206:531-539.

[61] Verstrynge E., Wevers M., Ghiassi B., Lourenço P.B. Debonding damage analysis in compositemasonry strengthening systems with polymer- and mortar-based matrix by means of the acoustic emission technique. Smart Materials and Structures 2016; 25(1):015009.

[62] Shetty N., Livitsanos G., Van Hemelrijck D., Aggelis D.G., Wevers M., Verstrynge E. Characterization of mechanical behaviour of masonry under compression using acoustic emission, in 8th International Conference on Acoustic Emission Kyoto, Japan. 2016. p. 365-370. 
[63] De Santis S., Tomor A.K. Laboratory and field studies on the use of acoustic emission for masonry bridges. Ndt \& E International 2013; 55:64-74.

[64] Shiotani T., Aggelis D.G., Makishima O. Global Monitoring of Large Concrete Structures Using Acoustic Emission and Ultrasonic Techniques: Case Study. Journal of Bridge Engineering 2009; 14(3):188-192.

[65] Ohtsu M. The history and development of acoustic emission in concrete engineering. Magazine of Concrete Research 1996; 48(177):321-330.

[66] Schechinger B., Vogel T. Acoustic emission for monitoring a reinforced concrete beam subject to four-point-bending. Construction and Building Materials 2007; 21(3):483-490.

[67] Shehadeh M., Steel J.A., Reuben R.L. Acoustic emission source location for steel pipe and pipeline applications: the role of arrival time estimation. Proceedings of the Institution of Mechanical Engineers Part E-Journal of Process Mechanical Engineering 2006; 220(E2):121-133.

[68] Shah S.P., Li Z. Localization of microcracking in concrete under uniaxial tension. ACI Materials Journal 1994; 91(4):372-381.

[69] Grosse C.U., Reinhardt H.W., Dahm T. Localization and classification of fracture types in concrete with quantitative acoustic emission measurement techniques. NDT \& E International 1997; 30(4):223-230.

[70] Carpinteri A., Lacidogna G., Niccolini G. Critical behaviour in concrete structures and damage localization by acoustic emission. Key Engineering Materials 2006; 312:305-310.

[71] Lacidogna G., Manuello A., Niccolini G., Accornero F., Carpinteri A. Acoustic emission wireless monitoring of structures, chapter 2, in Acoustic Emission and Related Non-destructive Evaluation Techniques in the Fracture Mechanics of Concrete, Ohtsu M., Editor. Woodhead Publishing: Cambridge. 2015. p.

[72] Livitsanos G., Shetty N., Verstrynge E., Wevers M., Van Hemelrijck D., aggelis D.G. AE source localization accuracy optimization in masonry structures, in 24th International Acoustic Emission Symposium (IAES-24): Sapporo, Japan. 2018. p. 145-150.

[73] Binda L., ed. Learning from Failure - Long-term behaviour of heavy masonry structures. Advances in Architecture. Vol. 23. WIT Press: Southampton. (2008).

[74] Verstrynge E., Schueremans L., Van Gemert D., Hendriks M.A.N. Modelling and analysis of timedependent behaviour of historical masonry under high stress levels. Engineering Structures 2011; 33(1):210-217.

[75] Tomor A.K., Melbourne C. Condition monitoring of masonry arch bridges using acoustic emission techniques. Structural Engineering International 2007; (2):188-192.

[76] Shigeishi M., Colombo S., Broughton K.J., Rutledge H., Batchelor A.J., Forde M.C. Acoustic emission to assess and monitor the integrity of bridges. Construction and Building Materials 2001; 15(1):35-49.

[77] Invernizzi S., Lacidogna G., Manuello A., Carpinteri A. AE Monitoring and Numerical Simulation of a Two-span Model Masonry Arch Bridge Subjected to Pier Scour. Strain 2011; 47:158-169.

[78] Verstrynge E. Long-term behaviour of monumental masonry constructions: modelling and probabilistic evaluation. PhD Thesis. Civil Engineering Department, KU Leuven: Leuven. 2010.

[79] Olaszek P., Casas J.R., Świt G. On-site assessment of bridges supported by acoustic emission. Proceedings of the Institution of Civil Engineers - Bridge Engineering 2016; 169(2):81-92.

[80] Wu Y., Li S., Wang D., Zhao G. Damage monitoring of masonry structure under in-situ uniaxial compression test using acoustic emission parameters. Construction and Building Materials 2019; 215:812-822.

[81] Carpinteri A., Lacidogna G., eds. Earthquakes and Acoustic Emission: Selected Papers from the 11th International Conference on Fracture, Turin, Italy, March 20-25, 2005. CRC Press. (2007). 
[82] Carpinteri A., Lacidogna G., eds. Acoustic Emission and Critical Phenomena: From Structural Mechanics to Geophysics, selected contributions from the 6th International Conference on Fracture Mechanics of Concrete and Concrete Structures (FraMCoS-6), Catania, Italy, 22 June 2007. CRC Press. (2008).

[83] Carpinteri A., Lacidogna G., Manuello A. The b-value analysis for the stability investigation of the ancient Athena Temple in Syracuse. Strain 2009; 47:243-253.

[84] Carpinteri A., Lacidogna G., Invernizzi S., Manuello A., Binda L. Stability of the vertical bearing structures of the Syracuse Cathedral: experimental and numerical evaluation. Materials and Structures 2009; 42(7):877-888.

[85] Niccolini G., Carpinteri A., Lacidogna G., Manuello A. Acoustic emission monitoring of the Syracuse Athena Temple: Scale invariance in the timing of ruptures. Physical Review Letters 2011; 106(108503):1-4.

[86] Carpinteri A., Lacidogna G., Niccolini G. Fractal analysis of damage detected in concrete structural elements under loading. Chaos, Solitons \& Fractals 2009; 42(4):2047-2056.

[87] Carpinteri A., Lacidogna G., Niccolini G. Medieval towers as sensitive earthquake receptors, in 5th International Seminar on Structural Analysis of Historical Constructions, Lourenco P.B., et al., Editors: New Delhi. 2006.

[88] Niccolini G., Borla O., Accornero F., Lacidogna G., Carpinteri A. Scaling in damage by electrical resistance measurements: An application to the terracotta statues of the Sacred Mountain of Varallo Renaissance Complex (Italy). Rendiconti Lincei Scienze Fisiche Naturali 2014; 26:203-209.

[89] Alexakis H., Franza A., Acikgoz S., DeJong M.J. Monitoring Bridge Degradation Using Dynamic Strain, Acoustic Emission and Environmental Data, in International Conference on Smart Infrastructure and Construction 2019 (ICSIC). 2019. p. 523-532.

[90] Holford K.M. Acoustic Emission in Structural Health Monitoring. Key Engineering Materials 2009; 413-414:15-28.

[91] Royles R. Acoustic emission monitoring of masonry arch bridges. British Journal of NDT 1991; 33(7):339-343.

[92] Accornero F., Lacidogna G., Carpinteri A. Medieval arch bridges in the Lanzo Valleys, Italy: Incremental structural analysis and fracturing benefit. Journal of Bridge Engineering ASCE 2018; 23(7).

[93] Tomor A.K., Melbourne C. Monitoring masonry arch bridge response to traffic loading using acoustic emission techniques, in 5th International Conference on Masonry Arch Bridges: Funchal, Madeira. 2007. p. 281-288. 